\title{
Study of Modal Behaviour of Sandwich Structure with Various Core Materials - An Analytical Approach
}

\author{
Krishanu Gupta ${ }^{*}$, Prasun Chakraborti, Chiranjit Bhowmik \\ Department of Mechanical Engineering, National Institute of Technology Agartala, Tripura 799046, India
}

Corresponding Author Email: krishanu.me@ @ita.ac.in

https://doi.org/10.18280/rcma.300103

Received: 21 July 2019

Accepted: 4 November 2019

\section{Keywords:}

sandwich beam, free vibration, geometry, honeycomb, core, deformation

\begin{abstract}
The present study comprises of different types of cored sandwich structures with different core geometries. A combination of materials of skins and cores were considered to investigate the free vibrational or modal behaviour on the core materials and geometries for the structure for illuminating the vibrational aspects for failures. Subsequently, the deformation for sandwich structures with various core geometries and materials was also studied. The objective of the article is to provide an essence of vibrational performance study of aluminium alloy for both skins, and the results were compared among core materials unlike materially configured sandwich structures of honeycomb core. Simulations of mode shapes were obtained using the free vibrational constraints. From this study, it was obtained that, two types of core geometries strictly imply that there is obvious effect of shape of core in sandwich beam vibrational characteristics of structure, as in the study. Lastly, the results obtained by using honeycomb core geometry of certain material was compared to regular rectangular geometrized core and found to have better results in terms of natural frequencies and maximum deformation of the later. Thus, findings may serve as a case for application of similar structures in engineering applications.
\end{abstract}

\section{INTRODUCTION}

Non-conventional structures have become a prominent in various engineering practices viz., automobile, aircraft, aerospace, etc., industries due their ample advantages in case of their improved geometries, excellent characteristics in terms of strength, weight, etc. Thus, design and analyses of these structures has become an important arena of research in modern days building engineering. One of the referred structures is the sandwich beams (SB), which are generally light in weight with good stiffness and strength physiognomies. A sandwich structure consists of three fragments, namely, a core and two faces, binding the core. The material in the core lays a crucial impact on the overall performance of the beam. The concept of sandwich structure comprises of a combination of different materials for the skin and the core, as for which the properties of individual materials comply to the overall property enhancement of the structure, viz., the elastic property of skins and cores combine to yield an enhanced overall elastic property of the structure. Thus, the vibrational characteristic study of these type of materials are very vital for attaining an improved structure, when compared to other structures manufactured using virgin materials, and applying those materials in a broaden engineering extremity, with some kind of improved geometries. The increased demand for the sandwich structures as advantageous to be a stiffer, light weighing structure, have drawn researchers to study upon different parameters so as to improve the overall properties of sandwich structures. A study with core latticed truss [1] used Hamilton's principle for calculation of natural frequencies and compared with numerical simulations for mode shapes. Galerkin technique was applied for a functionally graded cored SB, with similar face sheets and found the first 10 nodes and were compared with finite element method. Similar analyses were also carried out for SBs with elastic/viscoelastic core using a discrete green function for finding the flexural behaviour under concentrated loading condition [2].

One of the prominent core structures that are used for different engineering and structural applications is a honeycomb type structure. The basic concept of a honeycomb structure is as simple as that of honeycombs made by bees. In another study for the modal behaviour of sandwich structures [3], aluminium honeycomb were considered as the material for the core with two low dense flat skin sheets. The results that were obtained by FE analyses were compared to an experimental set results and they concluded with good agreement in results. The adoption of these style of structures is first of all, for attaining a structure that can reduce the overall weight of the structure, as the sandwich beams/structures find applications mostly in aerospace, aircraft, naval, etc., fields where, one of the aims for building smart structures by reducing the weight [4] studied hexagonal honeycomb plates for their vibrational characteristics, that would be applied to satellite structures, where, in addition to lightweight, a high specific bending stiffness and good strength under distributed loads are also requisite, where, the skin and core materials for the sandwich structure was considered to be as aluminium sheets and aluminium honeycomb respectively. Henceforth, it was concluded that experimental results and finite element (FE) modal results 
were in good agreement to each other. A study carried out for the free vibration characteristics of delaminated honeycomb sandwich beams (HCSB) [5]. For the analytical study, an analysis platform was used that would expose the quantity of damage along with the natural frequencies and corresponding mode shapes, for different sandwich plates considering intact and debonded conditions of honeycomb structures. To draw conclusion, natural frequencies for debonded condition showed a dwindled trend when compared to the intact core condition. A study for a graded aluminium honeycomb sandwich structures for determination and investigation of mechanical and physical properties theoretically [6]. Thermoset resins were used for binding the faces and core of the sandwich beam. Cohesive Zone Modelling (CZM) was discussed [7] which deals with the non-linear region afore the crack-tip zone, consequent to micro-cracking or plasticity. CZM, when compared to Linear Elastic Fracture Mechanics (LEFM) proved to be advantageous in the numerical study because of the drawback of LEFM that assumes at first the material to be isotropic and linearly elastic, and consequently not allowing the characterization of the entire fracture process. Some researchers also studied the free vibrational characteristics of SBs using FE method [8] to find the natural frequencies at different mode shapes using various materials of skin and core, with some concepts of layered beams [3, 9, 10]. Studies for the free vibration of irregular honeycomb core SB concluded that geometries of core do affect on natural frequencies of panels [11, 12]. Another study [13] for sandwich structure prepared with textile reinforced composite for fire resistant behaviours also revealed the dependence of characteristics on core materials. For the natural frequency analysis of a cantilever beam, with different materials aluminium, mild steel and copper showed experimental results were in good agreement with analytical results [14]. Researcher in a study [15] used dynamic stiffness technique for analyzing free vibrational characteristics of a 3-layered symmetric sandwiched panel and concluded that the proposed theory would be helpful for complex sandwich panels. Researcher studied aluminium honeycomb SB for revealing vibrational characteristics using experimentation and analytical techniques, showing cell angle of honeycomb, core geometry had effect on natural frequency of the SB [16].

The literature study revealed that some more arena may be explored for analyzing free vibrational characteristics of these smart structures so that these structures may be applied to various engineering applications, where, conventional structures may be replaced with these structures. Thus, the present study reveals that some modifications to the core geometry and materials effects the natural frequency results at different modes, considered the first six, in this case.

\section{THEORETICAL MODAL ANALYSIS}

Vibration analysis can be categorized depending upon their linearity and non-linearity. Linear vibration analysis is those where the mass, stiffness and damping matrices are constant and do not vary with respect to time. The study of vibration or modal analysis in the present work is limited to a linear vibration. In the present study, the modal analyses of sandwich structures are carried out in a pre-stressed condition, in which no external forces or moments were applied and the Eq. 1 has been modified according to present condition, motivated from a study [17] for sandwich panel with a viscoelastic core, where the beam was considered to be in a cantilever condition.

Free vibration motion equation with no damping for a threelayer sandwich panel.

$$
[\mathrm{M}]\{\ddot{\mathrm{X}}\}+[\mathrm{S}]\{\mathrm{X}\}=\{0\}
$$

For harmonic oscillations $\{\mathrm{X}\}=\left\{\mathrm{X}_{0}\right\}$ sin $\omega \mathrm{t}$, characteristic equation of Eq. (1) [18]:

$$
\left([\mathrm{S}]-\omega^{2}[\mathrm{M}]\right)\left\{\mathrm{X}_{0}\right\}=\{0\}
$$

A condition when Eq. (2) has a non-zero solution:

$$
\left|[\mathrm{S}]-\omega^{2}[\mathrm{M}]\right|=0
$$

The frequencies of a system are obtained from the solution of Eq. (3), and the Eigenvalues and Eigenvectors of the characteristic equation are the free vibration frequencies and the corresponding vibration modes.

\section{SANDWICH COMPONENTS MODELLING AND MATERIALS}

The laminated sandwich structures have numerous advantages to diverse fields of engineering and constructional applications, and for a better performance of these structures, the materials involved for core and skin plays a vital role in the overall performance of sandwich beams/structures. Thus, for the current study, a set of material combinations for the skins and honeycomb core have been considered in four different cases keeping materials for core constant and varying skin materials as in Table 1:

Table 1. Material combination for sandwich beams

\begin{tabular}{ccc}
\hline \multirow{2}{*}{ Cases } & \multicolumn{2}{c}{ Materials } \\
\cline { 2 - 3 } & Skin & Core \\
\hline I & Aluminium alloy & Honeycomb core Al alloy \\
II & Aluminium alloy & Rectangular core Al alloy sheet \\
III & Aluminium alloy & Rectangular core Steel alloy sheet \\
\hline
\end{tabular}

The mechanical properties that are considered for input in analyzing the natural frequency characteristics in the FE platform for the mentioned types of sandwich beams. The assigned properties of chosen materials for sandwich panel skin and core are shown in Table 2.

Table 2. Material properties of skin and core

\begin{tabular}{ccccc}
\hline \multirow{2}{*}{$\begin{array}{c}\text { Sl. } \\
\text { No. }\end{array}$} & \multirow{2}{*}{ Material } & \multicolumn{3}{c}{ Mechanical Properties } \\
\cline { 3 - 5 } & & $\begin{array}{c}\text { Density } \\
\left(\mathrm{kg} / \mathrm{m}^{3}\right)\end{array}$ & $\begin{array}{c}\text { Young's } \\
\text { Modulus (MPa) }\end{array}$ & $\begin{array}{c}\text { Poisson's } \\
\text { Ratio }\end{array}$ \\
\hline 1. & Aluminium alloy & 2770 & 71000 & 0.33 \\
2. & Steel & 7850 & 200000 & 0.3 \\
\hline
\end{tabular}

Sandwich panels or beams (SB) are a multi-layered structure of three elements, entailing of two metallic or nonmetallic faces and a core which binds the two faces. The material in the core considered in the present study is a honeycomb structured, between the two metallic faces. The elasto-plastic behaviour for sandwich laminated structures is studied by interfacial analyzing of skins and core. 


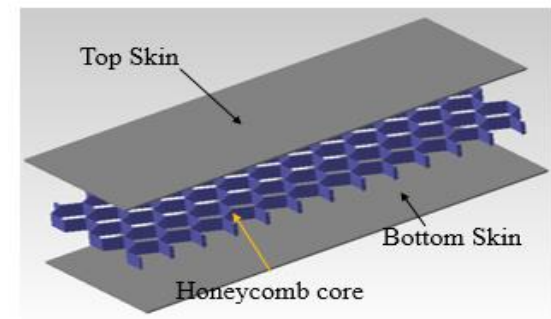

(a) Honeycomb Cored SB

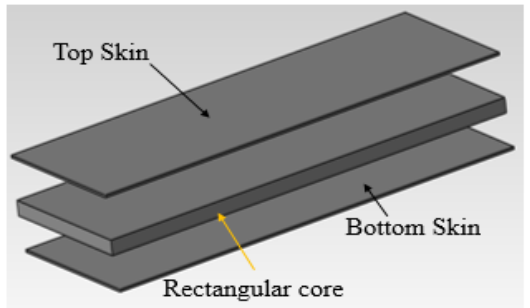

(b) Rectangular Cored SB

Figure 1. Sandwich panel types and components

A laminated sandwich panel consist of two basic components, one of which is the core which are bounded by two skins on both sides, shown in Figure 1, with dimensions for the core and the skin has been detailed, according to ASTM C393 [19] in Table 3.

Table 3. Dimensional considerations of sandwich panel

\begin{tabular}{ccc}
\hline \multirow{2}{*}{ Parameters } & \multicolumn{2}{c}{ Components dimension (mm) } \\
\cline { 2 - 3 } & Core & Skin \\
\hline Length & 200 & 200 \\
Width & 75 & 75 \\
Thickness & 6 & 1 \\
\hline & & \\
& & \\
\end{tabular}

(a) Rectangular core

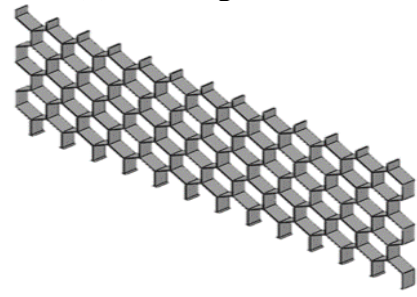

(b) Honeycomb core

Figure 2. Sandwich panel core types

The regular rectangular configuration for the current study that has been considered to be a unique configuration as shown in Figure 2 (a) and the frame of the honeycomb core in Figure 2 (b). The combination of advantages a sandwich structured core in sandwich panels offers, viz., improved strength, stability, light in weight, etc., has made the applications of these structures in almost all regime of engineering applications. Some attempts were also made by several researchers to investigate modal behaviour of debonded sandwich structures with fiber epoxy honeycomb cores [20].

Thus, an attempt has been made in this article by the authors to investigate that region which also plays a very prominent role in the failure characteristics of sandwich structures, considering a metallic honeycomb material and regular rectangular core to reveal their vibrational characteristics for various engineering applications.

\section{MODAL BEHAVIOUR AND ANALYSIS}

Natural frequency, deformation, and mode shapes are the three essential fragments used to illustrate the dynamic characteristics of any mechanical structure. In order to find out the first six mode shapes or the eigenvectors and natural frequencies of sandwich panels with various combination of core materials using 3D FE method, mesh representation or discretization of elements is an important requirement for obtaining result that is close to accuracy in the finite element method [21]. In the present study for natural frequencies and mode shape/eigenvectors, meshing is carried out with maximum edge length of $3 \mathrm{~mm}$, since, there is no load/force applied and also to reduce a much of computational time. For the sandwich panel with honeycomb core (Figure 3), the number of nodes and elements here has been found to be 38131 and 13094 respectively; and correspondingly, for the beam with rectangular metallic core, 43542 and 20100 number of nodes and elements with Solid186 and Conta174-Targe170 element types were used for solid components and adhesive contact faces respectively.

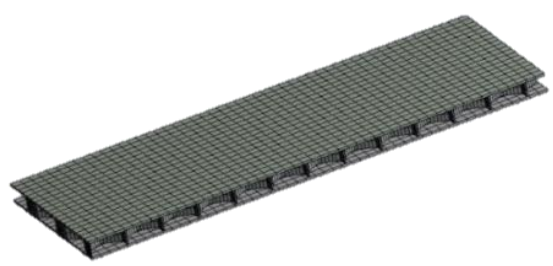

Figure 3. FE mesh result for the honeycomb cored sandwich panel

\subsection{Mode shape analyses of sandwich panels}

As discussed in the previous sections, modal analysis is study of the natural frequencies and mode shape calculations. Thus, in this segment of the article, the different mode shapes and natural frequencies of different cases of sandwich panels are the found out results. The deformed shapes of the sandwiched structure at specific natural frequencies of vibration are its normal modes of vibration. Several other rapports used to illustrate the normal mode are mode shapes, characteristic shapes, and fundamental shapes. Each mode shape is associated with a specific natural frequency which are also the eigenvectors, which in this study six mode shapes has been considered. The condition of supports for the analysis of mode shapes and frequencies has been considered to be in simply supported condition with one end fixed in all directions and the other end allowed to move in horizontal direction and fixed in other two directions.

The mode shapes for the several cases considered as mentioned in previous section has been shown below from Figures 4 to 6 .

Case- I: Skin: Aluminium alloy, Rectangular core: Al alloy sheet. 


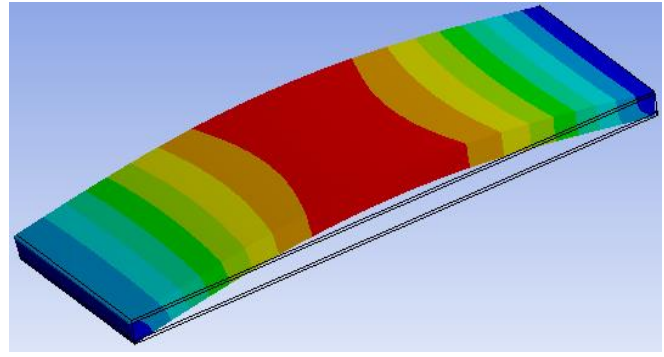

(a) $1^{\text {st }}$ Mode Shape

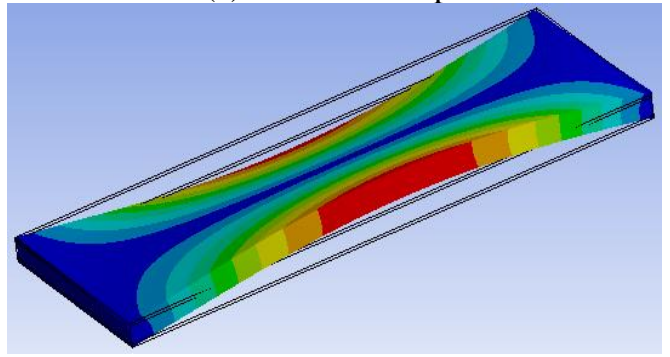

(b) $2^{\text {nd }}$ Mode Shape

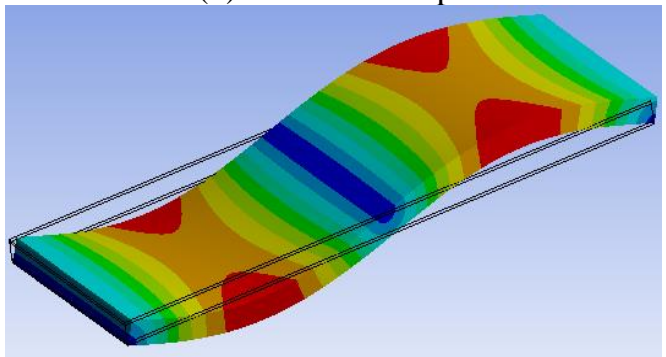

(c) $3^{\text {rd }}$ Mode Shape

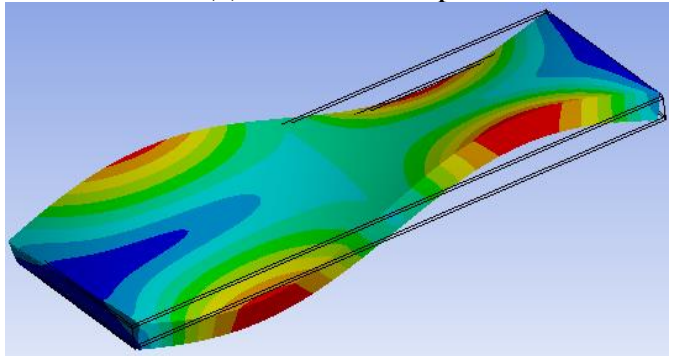

(d) $4^{\text {th }}$ Mode Shape

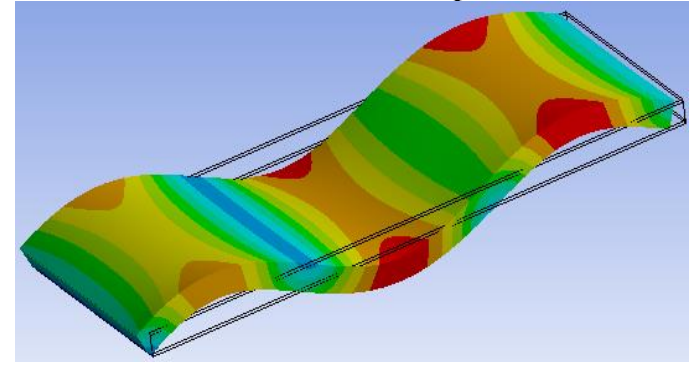

(e) $5^{\text {th }}$ Mode Shape

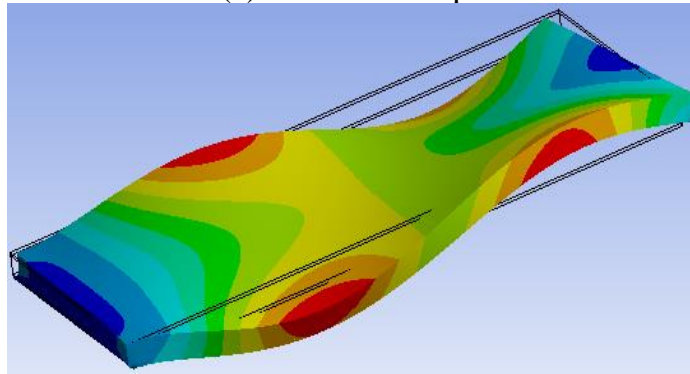

(f) $6^{\text {th }}$ Mode Shape

Figure 4. Different mode shapes for Case I

Case- II: Skin: Aluminium alloy, Rectangular core: Steel.

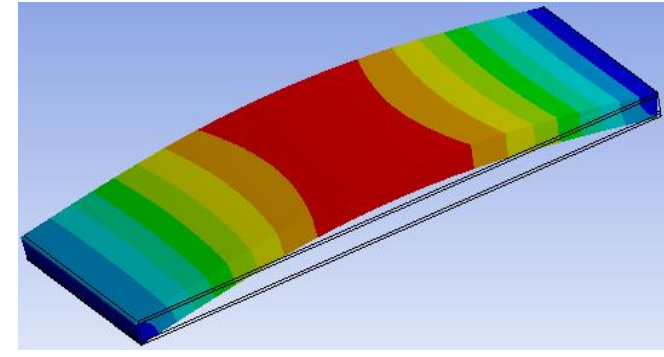

(a) $1^{\text {st }}$ Mode Shape

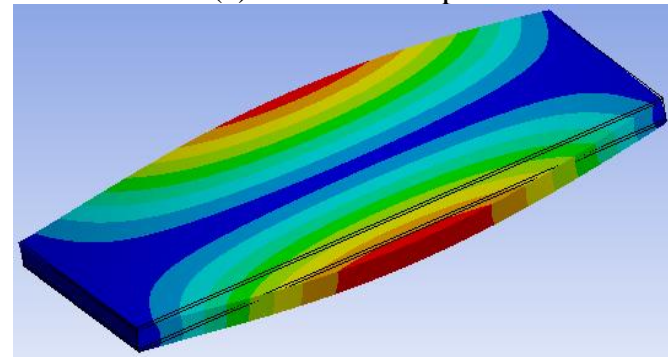

(b) $2^{\text {nd }}$ Mode Shape

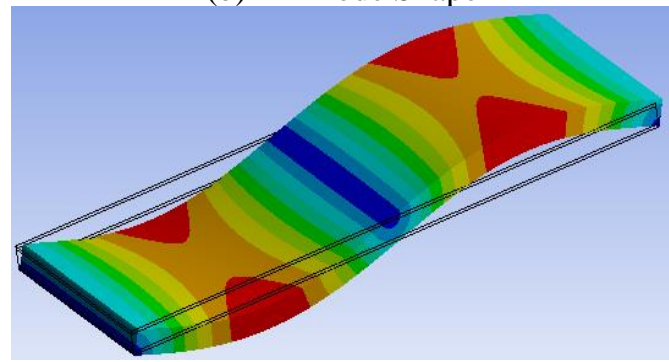

(c) $3^{\text {rd }}$ Mode Shape

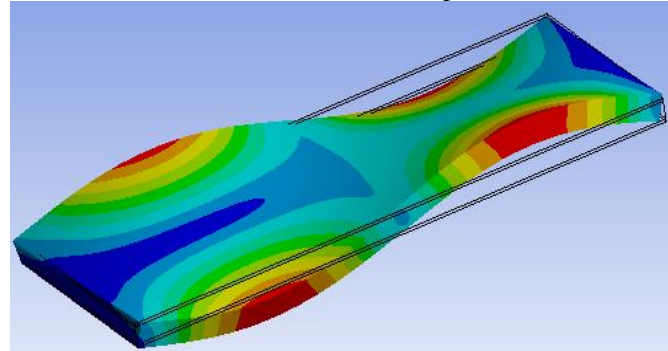

(d) $4^{\text {th }}$ Mode Shape

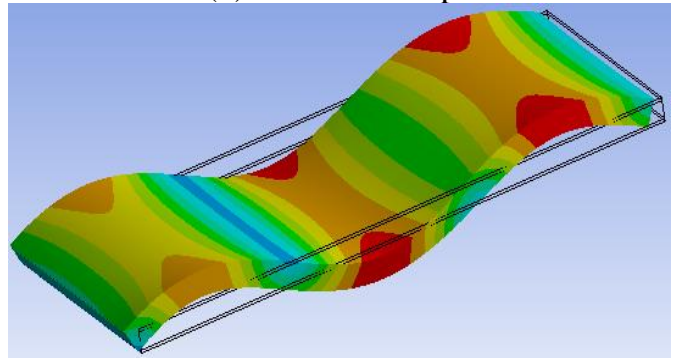

(e) $5^{\text {th }}$ Mode Shape

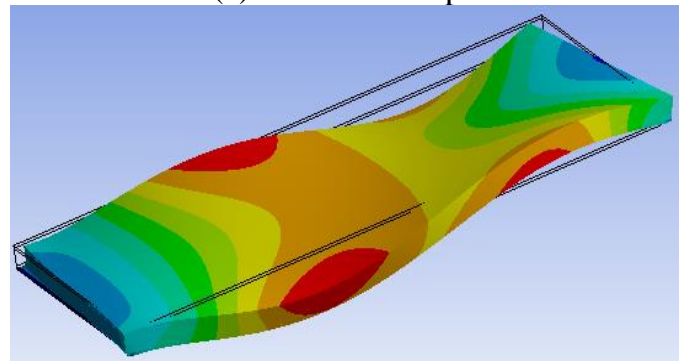

(f) $6^{\text {th }}$ Mode Shape

Figure 5. Different mode shapes for Case II

Case- III: Skin: Aluminium alloy, Honeycomb core: Aluminium alloy. 


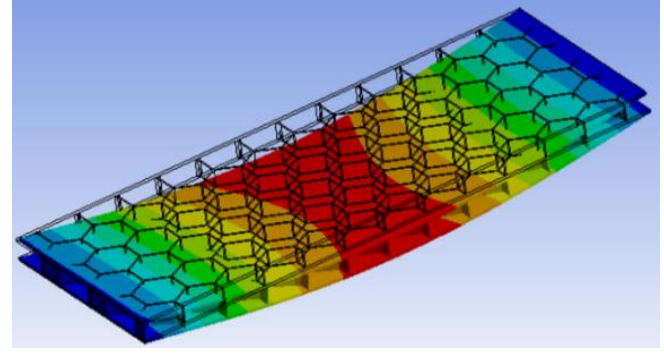

(a) $1^{\text {st }}$ Mode Shape

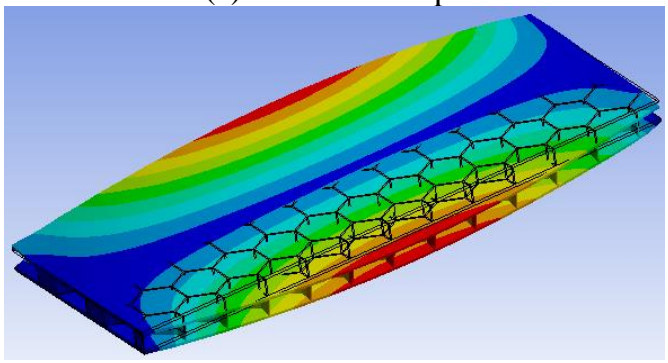

(b) $2^{\text {nd }}$ Mode Shape

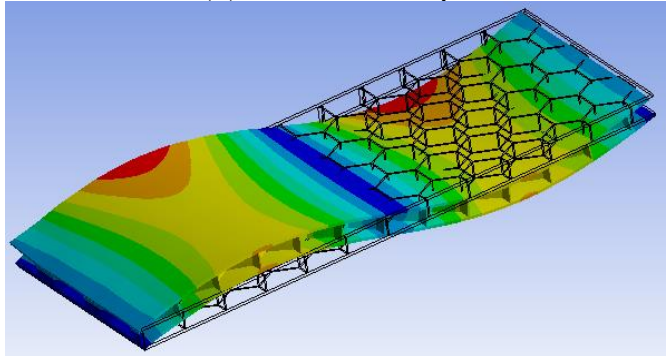

(c) $3^{\text {rd }}$ Mode Shape

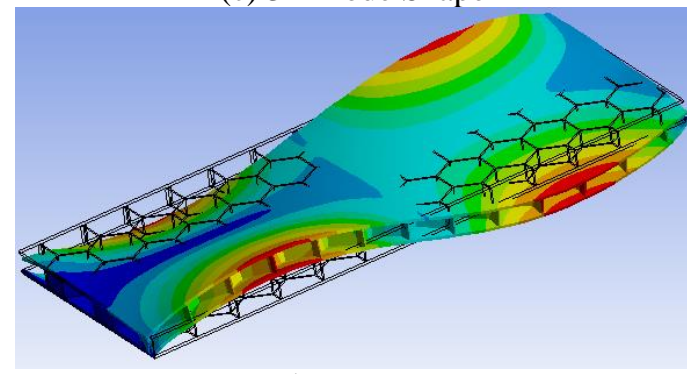

(d) $4^{\text {th }}$ Mode Shape

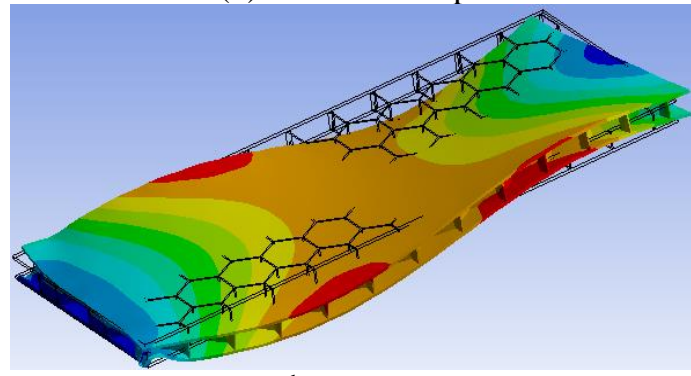

(e) $5^{\text {th }}$ Mode Shape

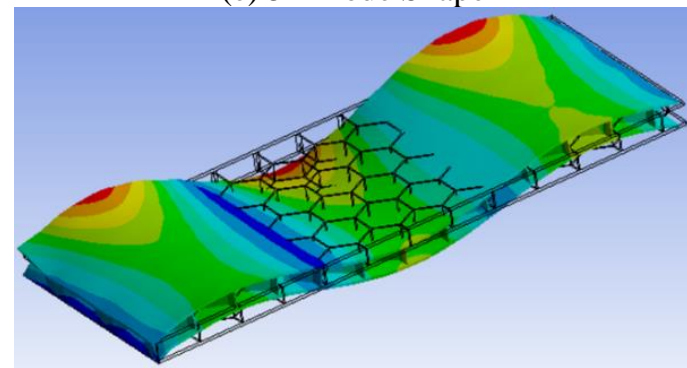

(f) $6^{\text {th }}$ Mode Shape

Figure 6. Different mode shapes for Case III
Graphical results have been presented for natural frequencies of the sandwich panels corresponding to modes with different degree of structural irregularity in rectangular and honeycomb cores that were obtained by analytical iterative method, where the un-deformed shape is also wireframed along with the deformed shapes for all the eigenvectors. Analytical results obtained have been documented has been processed are shown in graphical representation in Figure 7 and the maximum deformation results for the selected core are shown in Figure 8.

From the above graphical representations for both aluminium and steel skin sandwich beams, it may be observed that natural frequencies for the honeycomb materials with aluminium alloy values were compared to that of rectangular cored materials. In the present article, authors made an attempt to study the natural frequencies of rectangular shaped natural rubber and honeycomb structured core sandwich beams and the corresponding deformation at mode shapes are inquired that are detailed in Table 4.

From the results in the Table 4 for maximum deformation indicates that the trend of deformation values has increased for any corresponding mode in any skin condition for except some concessions, which implies that metallic honeycomb core materials are prone to failure under vibration when considered in a simply supported load condition.

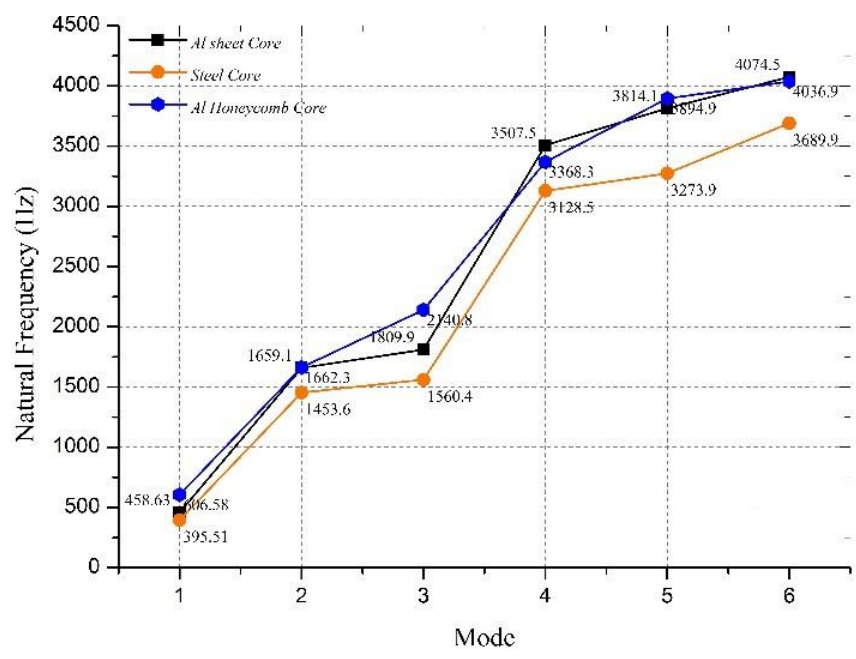

Figure 7. Natural frequency vs mode shape (Eigenvector) results for aluminium skin SBs

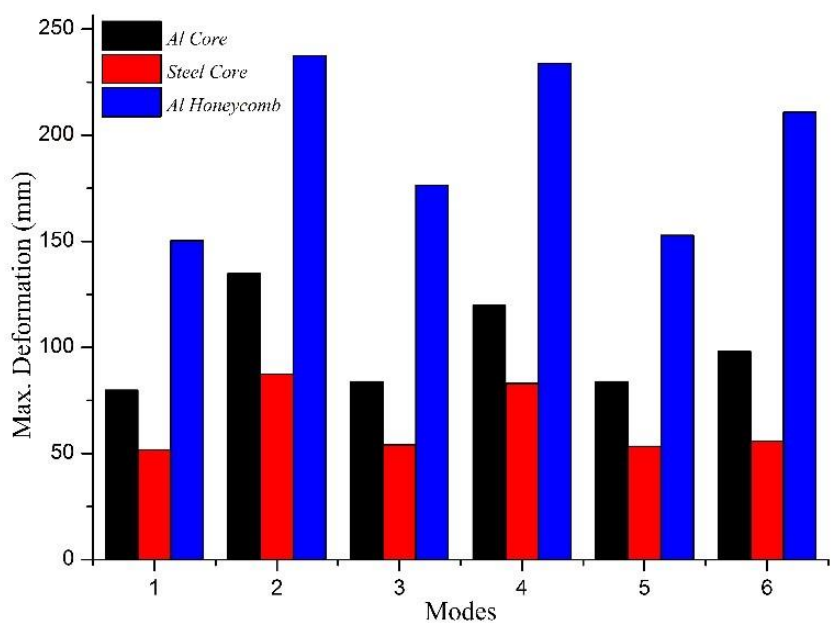

Figure 8. Maximum deformation at various mode results for sandwich panels 
Table 4. Maximum deformation at different modes

\begin{tabular}{cccccccc}
\hline \multirow{2}{*}{ S1. } & \multirow{6}{*}{ Case } & \multicolumn{6}{c}{ Mode Shapes } \\
\cline { 3 - 7 } No. & & 1 & 2 & 3 & 4 & 5 & 6 \\
\cline { 3 - 7 } & \multicolumn{7}{c}{ Maximum Deformation (mm) } \\
\hline 1 & I & 79.8 & 134.8 & 83.9 & 119.8 & 83.9 & 98 \\
2 & II & 51.7 & 87.5 & 54.0 & 82.9 & 53.5 & 55.7 \\
3 & III & 150.2 & 237.6 & 176.3 & 233.9 & 152.7 & 210.9 \\
\hline
\end{tabular}

\section{CONCLUSION}

From the mode shape analyses carried out for some conditions of honeycomb cored sandwich beams/ structures, some conclusions may be drawn. The loading condition for the sandwich structure that has been considered to be a simply supported or three points bending. For the mentioned loading condition, the honeycomb core with a geometry as described following ASTM standard for short sandwich beams. The natural frequencies for the four conditions with different core material combination were found out that reveals maximum value for aluminium alloy sheet core to be $4074.5 \mathrm{~Hz}$ and for aluminium $\mathrm{HC}$ core to be $3689.90 \mathrm{~Hz}$. On contrary to the above results, the overall weight of the beam has found to be reduced by over $70 \%$ for honeycomb cored when compared to regular rectangular sandwich beam. The authors found that the natural frequency values of aluminium sheet cored SB is not much greater than that of honeycomb core of same material, but when compared in terms of the overall weight of the beam. Thus, for a huge decrement in the overall weight, a honeycomb cored may be preferred over the regular cored beam.

In conclusion, it may also be mentioned that future research may be carried out with various geometries of core and their vibrational effects on the overall performance of sandwich panels.

\section{ACKNOWLEDGMENT}

The authors wish to acknowledge the Department of Mechanical Engineering at National Institute of Technology Agartala for providing computational facilities, and, also to those who directly or indirectly helped in completion of the article. Also, the authors would like to thank those resources that are available in open-sources.

\section{REFERENCES}

[1] Wu, L.Z., Lou, J., Ma, L. (2012). Free vibration analysis of simply supported sandwich beams with lattice truss core. Materials Science and Engineering: B, 177(19): 1712-1716. https://doi.org/10.1016/B978-0-12-8109984.00007-7

[2] Sakiyama, T., Matsuda, H., Morita, C. (1996). Free vibration analysis of continuous sandwich beams with elastic or viscoelastic cores by applying the discrete Green function. Journal of Sound and Vibration, 198(4): 439-454. https://doi.org/10.1006/jsvi.1996.0581

[3] Shrigandhi,G.D., Deshmukh, P. (2011). Modal analysis of composite sandwich panel. International Journal of Current Engineering and Technology, 4(4): 259-264. http://dx.doi.org/10.14741/Ijcet/22774106/spl.4.2016.53

[4] Boudjemai, A., Amri, R., Mankour, A., Salem, H., Bouanane, M.H., Boutchicha, D. (2012). Modal analysis and testing of hexagonal honeycomb plates used for satellite structural design. Materials and Design, 35: 266275. https://doi.org/10.1016/j.matdes.2011.09.012

[5] Madhukumar, A., Nisha, A.S. (2016). Free vibration analysis of delaminated honeycomb sandwich composite plates. International Journal of Scientific \& Engineering Research, 7(10): 141-148.

[6] Rajkumar, S., Arulmurugan, B., Manikandan, M., Karthick, R., Kaviprasath, S. (2017). Analysis of physical and mechanical properties of A3003 aluminum honeycomb core sandwich panels. Applied Mechanics and Materials, 867: 245-253. https://doi.org/10.4028/www.scientific.net/AMM.867.2 45

[7] Pinto, A.M.G., Campilho, R.D.S.G., Mendes, I.R., Baptista, A.P.M. (2014). Numerical and experimental analysis of balanced and unbalanced adhesive single-lap joints between aluminium adherends. The Journal of Adhesion, $\quad 90(1)$ : 89-103. https://doi.org/10.1080/00218464.2013.773258

[8] Lashin, M.M.A., El-Nady, A.O. (2015). Free vibration analysis of sandwich beam structure using finite element approach. IOSR Journal of Mechanical and Civil Engineering, 12(6): 34-42. https://doi.org/10.9790/168412613442

[9] Banerjee, J.R., Cheung, C.W., Morishima, R., Perera, M., Njuguna, J. (2007). Free vibration of a three-layered sandwich beam using the dynamic stiffness method and experiment. International Journal of Solids and Structures, $\quad 44(22-23)$ : 7543-7563. https://doi.org/10.1016/j.ijsolstr.2007.04.024

[10] Rajesh, C., Kumar, S.J. (2016). Free vibration analysis of various viscoelastic sandwich beams. Indian Journal of Science and Technology, 5(6): 566-570.

[11] Mukhopadhyay, T., Adhikari, S. (2016). Free-vibration analysis of sandwich panels with randomly irregular honeycomb core. Journal of Engineering Mechanics, 142(11).

[12] Ramesh, B.V., Vasudevan, R., Kumar, N.B. (2014). Vibration analysis of a laminated composite magnetorheological elastomer sandwich beam. Applied Mechanics and Materials, 592-594: 2097-2101. https://doi.org/10.4028/www.scientific.net/AMM.592594.2097

[13] Shen, L.H., Wang, J.Y., Xu, S.L., Amoako-Atta, G. (2019). Fire resistance behavior of full-scale self-thermal insulation sandwich walls made of textile-reinforced concrete. International Journal of Heat and Technology, 37(1): 239-248. https://doi.org/10.18280/ijht.370129

[14] Mane, P.D., Yadav, A.A., Pol, A.M., Kumbhar, V.A. (2018). Comparative analysis of natural frequency for cantilever beam through analytical and software approach. International Research Journal of Engineering and Technology (IRJET), 5(2): 656-671.

[15] Banerjee, J.R. (2003). Free vibration of sandwich beams using the dynamic stiffness method. Computers and Structures, $\quad$ 81(18-19): https://doi.org/10.1016/S0045-7949(03)00211-6

[16] Şakar, G., Bolat, F.C. (2015). The free vibration analysis of honeycomb sandwich beam using 3D and continuum model. International Journal of Mechanical, Aerospace, Industrial, Mechatronic and Manufacturing Engineering, 9(6): 1077-1081.

[17] Arvin, H. (2014). Frequency response analysis of higher 
order composite sandwich beams with viscoelastic core. Iranian Journal of Science and Technology Transactions of Mechanical Engineering, 38(M1): 143155.

[18] Zhuang, W.Z., Yang, C., Wu, Z.G.(2019). Modal and aeroelastic analysis of trapezoidal corrugated-core sandwich panels in supersonic flow. International Journal of Mechanical Sciences, 157-158: 267-281. https://doi.org/10.1016/j.ijmecsci.2019.04.052

[19] ASTM Standard C393/C393M-06. (2006). Standard Test Method for Core Shear Properties of Sandwich Constructions by Beam Flexure, ASTM International, West Conshohocken, PA.

[20] Kim, H.Y., Hwang, W. (2002). Effect of debonding on natural frequencies and frequency response functions of

honeycomb sandwich beams. Composite Structures, 55(1): 51-62. https://doi.org/10.1016/S02638223(01)00136-2

[21] Gokhale, N.S., Deshpande, A., Bedekar, S.V. (2008). Practical Finite Element Analysis. International Edition.

\section{NOMENCLATURE}

[S]

$[\mathrm{M}]$

$\{\mathrm{X}\}$ $\omega$

$\{\ddot{X}\}$
Stiffness matrix Mass matrix

Nodal displacement vector Natural frequency

Nodal acceleration vector 